\title{
The Laminar Development of Direction Selectivity in Ferret Visual Cortex
}

\author{
Jared M. Clemens, Neil J. Ritter, Arani Roy, Julie M. Miller, and Stephen D. Van Hooser \\ Department of Biology, Brandeis University, Waltham, Massachusetts 02454
}

Sensory experience plays a critical role in the development of cortical circuits. At the time of eye opening, visual cortical neurons in the ferret exhibit orientation selectivity, but lack direction selectivity, which is a feature of mature cortical neurons in this species. Direction selectivity emerges in the days and weeks following eye opening via a process that requires visual experience. However, the circuit mechanisms that underlie the development of direction selectivity remain unclear. Here, we used microelectrodes to examine the laminar chronology of the development of direction selectivity around the time of eye opening to identify the locations within the cortical circuit that are altered during this process. We found that neurons in layers 4 and 2/3 exhibited weak direction selectivity just before natural eye opening. Layer 4 neurons in animals that had opened their eyes but were younger than postnatal day 35 (PND 35) exhibited modestly increased direction selectivity, but layer $2 / 3$ cells remained as weakly tuned as before eye opening. Animals that had opened their eyes and were PND 35 or older exhibited increased direction selectivity in both layers 4 and 2/3. On average, initial increases in direction selectivity in animals younger than PND 35 were explained by increases in responses to the preferred direction, while subsequent increases in direction selectivity in animals PND 35 or older were explained by decreases in responses to the null direction. These results suggest that all cortical layers are influenced by sensory stimulation during early stages of experience-dependent development.

\section{Introduction}

During development, brain circuits are assembled through interactions between processes that are specified genetically and those that require sensory experience. In ferret visual cortex, neurons already exhibit orientation selectivity at the time of eye opening and are organized into orientation maps (Chapman and Stryker, 1993; Chapman et al., 1996; White et al., 2001). However, these neurons lack selectivity for a particular direction of motion, which is a property of mature cortical neurons in this species (Weliky et al., 1996; Moore et al., 2005). Further, visual experience is required for the proper maturation of cortical direction selectivity: dark-reared animals do not develop direction selectivity (Li et al., 2006), and, around eye opening, a few hours of experience with a moving stimulus, but not a flashing stimulus, is sufficient to produce the rapid emergence of direction-selective neurons and direction columns (Li et al., 2008).

The circuit mechanisms underlying the development of direction selectivity remain unclear. Previously, we found that the rapid development of direction selectivity following motion stimulation was limited to regions where the orientation preference matched the orientation of the training stimulus (Li et al.,

\footnotetext{
Received July 17, 2012; revised 0ct. 1, 2012; accepted 0ct. 31, 2012.

Author contributions: J.M.C., A.R., and S.D.V.H. designed research; J.M.C., N.J.R., A.R., and J.M.M. performed research; J.M.C., N.J.R., and S.D.V.H. analyzed data; J.M.C. and S.D.V.H. wrote the paper.

This study was supported by grants from the NIH and the Massachusetts Life Sciences Center to Brandeis University. We thank Jennifer Wolff, Heather Bernstein, and Ameya Apte for technical assistance and members of the Van Hooser laboratory for helpful discussions.

Correspondence should be addressed to Stephen D. Van Hooser at the above address. E-mail: vanhoosr@brandeis.edu.

DOI:10.1523/JNEUROSCI.3399-12.2012

Copyright $\odot 2012$ the authors $\quad 0270-6474 / 12 / 3218177-09 \$ 15.00 / 0$
}

2008). Because orientation selectivity is a property found in visual cortex, but not in lateral geniculate nucleus, changes within cortical circuits are sufficient to explain the development of direction selectivity. However, because previous studies relied on imaging techniques that could only observe the superficial layers, it remains unknown whether layer 4 neurons are already direction-selective at eye opening, or whether they develop direction selectivity following eye opening. Further, imaging studies of single neurons have used calcium dyes rather than direct recordings of spikes. Calcium signals can be nonlinearly related to spiking activity (Nauhaus et al., 2012), so it is unclear whether cells acquire direction selectivity through increases in spiking responses to the preferred direction, decreases in spiking responses to the opposite direction, or some combination. Here, we sought to clarify these issues by recording single units across cortical layers in young ferrets of different ages.

We examined the laminar chronology of the development of direction selectivity in ferret visual cortex around the time of eye opening. We devised a rapid sampling protocol to minimize visual stimulation provided to the animal, as substantial sensory experience would have altered the properties we sought to measure. At the level of spiking activity, visual cortical neurons exhibited increases in direction selectivity in the days following eye opening, similar to calcium imaging studies. Further, average responses to the preferred direction increased slightly in the first few days following eye opening, while over subsequent days, average responses to the opposite direction and the orthogonal orientation decreased. Layers 4 and 2/3 exhibited weak direction selectivity at the time of eye opening that increased substantially in the subsequent days, and layer 4 showed earlier increases in direction selectivity compared with layer $2 / 3$. These data suggest 
that plasticity mechanisms in layer 4 -whether in thalamocortical connections, intracortical connections, or both-may play key roles in the early phases of experience-dependent development of cortical circuits.

\section{Materials and Methods}

Ferrets ( 19 females, 4 males) ranging in age from postnatal day (PND) 28 to 63 were anesthetized intramuscularly with a mixture of ketamine $(20-40 \mathrm{mg} / \mathrm{kg})$ and xylazine $(4 \mathrm{mg} / \mathrm{kg})$. Atropine $(0.2 \mathrm{ml}$ of $0.4 \mathrm{mg} / \mathrm{ml})$ was administered to reduce bronchial and salivary secretion. A cannula was inserted into the intraperitoneal cavity for later delivery of neuromuscular blockers and nutrient ringer solution, a tracheostomy was performed, and the animal was placed in a custom stereotaxic frame that did not block vision. All wound margins were infused with the long-lasting analgesic bupivacaine. The animals were initially ventilated with $1.5-3 \%$ isoflurane in a 2:1 mixture of nitrous oxide and oxygen and silicon oil was placed on the eyes to prevent damage to the cornea. A small craniotomy $(4 \times 4 \mathrm{~mm})$ was made in one of the two hemispheres and the dura removed with a 31-gauge needle. At the conclusion of these procedures, ferrets were paralyzed with the neuromuscular blocker gallamine triethiodide $(0.2 \mathrm{mg} / \mathrm{h})$ to suppress spontaneous eye movements, and the nitrous oxide and oxygen mixture was adjusted to 1:1. The animal's EKG was continuously monitored to ensure adequate anesthesia, and the percentage of isoflurane was increased if the EKG indicated any distress. Body temperature was measured rectally and maintained at $37^{\circ} \mathrm{C}$ with a thermostatically controlled heating pad. All procedures were approved by the Brandeis Animal Care and Use Committee.

Carbon fiber electrodes (1 M $\Omega$, Carbostar-1, Kation Scientific) and tungsten electrodes $(0.1 \mathrm{M} \Omega$, part TM33B01, World Precision Instruments) were used to record from all layers of ferret cortex. The lower impedance tungsten electrodes were more effective at isolating cells in the youngest animals, whereas CarboStar-1 electrodes were most effective in older animals. Both electrode types were coated with fluorescent Di-I for later histological examination of recording site location (DiCarlo et al., 1996). Signals were amplified with a preamplifier/amplifier system by Multichannel Systems $\mathrm{GmbH}$ and acquired and clustered using a Micro1401 acquisition board and Spike2 software (Cambridge Electronic Design, LLC). Single-electrode recordings were used because initial attempts at multichannel recording (with NeuroNexus probes model A1x16-5mm-100-177-A16) did not produce high yields in the youngest animals (though they did in older animals).

During each penetration, the electrode was lowered in 75-100 $\mu \mathrm{m}$ increments, starting at the cortical surface and progressing to white matter. Characteristics of visual responses, such as adaptation, were noted and used as a preliminary attempt to map layer depths, which were later compared against histology. Upon completion of a penetration, electrolytic lesions were made at 2-3 depths to ensure accurate extrapolation of each recording's depth.

The depths of all cells and layer transitions were recorded digitally with a Sutter Instruments MP-285 manipulator. In all plots, cortical depths were combined across animals by projecting onto a "standard cortex" on a layer-by-layer basis. Depths of neurons recorded in layer $2 / 3$ were normalized (linearly) to be between $0 \mu \mathrm{m}$ (surface) and $450 \mu \mathrm{m}$ (layer 4 border), neurons in layer 4 were normalized to be between 450 and 900 $\mu \mathrm{m}$, and neurons in layer 5 and below were normalized to be between 900 and $1400 \mu \mathrm{m}$. Depths were readjusted using lesion depths, recorded depths, and custom software in Matlab.

Visual stimulation and data analysis. Visual stimuli were created in Matlab using the Psychophysics Toolbox (Brainard, 1997; Pelli, 1997) on a Macintosh Pro running OSX and displayed on a Sony (GDM-520). Spike tuning curves were analyzed with custom software in Matlab (Heimel et al., 2005; Van Hooser et al., 2006).

For each cell, we examined both the mean response to drifting grating stimulation ("F0") as well as the modulation at the stimulus frequency ("F1"). If a cell's F1 response was greater than the mean response (F0), then the F1 component was used to calculate index values. Otherwise, the F0 component was used (Movshon et al., 1978a,b; Heimel et al., 2005).
Direction selectivity was assessed using the circular variance (Ringach et al., 2002) calculated in direction space (Batschelet, 1981):

$$
1-\operatorname{DirCirVar}=\left|\frac{\sum_{k} R\left(\theta_{k}\right) \exp \left(i \theta_{k}\right)}{\sum_{k} R\left(\theta_{k}\right)}\right|,
$$

where $\theta_{k}$ are the direction angles used for stimulation and $R\left(\theta_{k}\right)$ is the response to angle $\theta_{k}$ (after subtraction of the spontaneous rate). This index is half of the traditional measure of "angular deviation" as defined by (Batschelet, 1981), but is convenient because the quantity varies between 0 and 1 . This $1-$ DirCirVar measurement was used because it is a robust measure for assessing direction selectivity for both poorly selective and strongly selective cells (Grabska-Barwińska et al., 2012). However, one should note that moderate values of $1-\operatorname{DirCirVar}(0.25-0.5)$ correspond to relatively high direction selectivity (Fig. 1a).

Orientation selectivity was also assessed using 1 minus the circular variance, calculated in orientation space (Ringach et al., 2002):

$$
1-\operatorname{CirVar}=\left|\frac{\sum_{k} R\left(\theta_{k}\right) \exp \left(2 i \theta_{k}\right)}{\sum_{k} R\left(\theta_{k}\right)}\right| .
$$

Immunohistochemistry. Following transcardial perfusion, the brain was removed and placed in $4 \%$ paraformaldehyde in $0.1 \mathrm{M}$ PBS for an additional $12-24 \mathrm{~h}$. The brain was then incubated in $10 \%$ sucrose for $24-48$ $\mathrm{h}$, followed by $30 \%$ sucrose for $24-48 \mathrm{~h}$. Frozen sections $(50 \mu \mathrm{m})$ from area V1 of the recording hemisphere were cut on a sliding microtome, parallel to the plane of the recording electrode by cutting sections in the parasagittal-horizontal anatomical plane. Sections were collected in $0.1 \mathrm{M}$ PBS, washed once for $5 \mathrm{~min}$ in PBS, and then agitated for $2 \mathrm{~h}$ in $0.3 \%$ Triton X-100 (MP Biomedicals, ICN807423) in $0.1 \mathrm{M} \mathrm{PBS}$ at room temperature. After three 5 min washes in PBS, sections were incubated in fluorescent Anti-NeuN (Millipore, MAB377x, 1:100) diluted in $0.1 \mathrm{M}$ PBS overnight $(>12 \mathrm{~h})$ at $4^{\circ}$ Celsius on a shaker. Sections were then rinsed 3 times, 5 min each, in PBS, mounted on slides, and coverslipped with Fluoromount-G (Cell Lab, 731604). Slices were then scanned with a Leica SP2 confocal microscope $(10-20 \times)$ and adjacent images were stitched together using Adobe Photoshop.

\section{Results}

Our goal was to characterize the development of direction selectivity at the level of spiking activity in layers $2 / 3$ and 4 . We studied 3 groups of animals: animals aged PND 28-34 that had not yet naturally opened their eyes ("eyes closed"), animals aged PND 28-34 that had naturally opened their eyes ("eyes open, PND $<35$ "), and animals aged PND 35-65 that had naturally opened their eyes between 4 and $30 \mathrm{~d}$ before the experiment (“eyes open, $\mathrm{PND} \geq 35$ ”). All ferrets were raised in a $12 \mathrm{~h}$ alternating light/dark laboratory environment, so the event of eye opening corresponded to the onset of patterned visual experience. Ferrets typically open their eyes around PND 30-32, so animals that had naturally opened their eyes aged $\mathrm{PND}<35$ would have had $\sim 0-4 \mathrm{~d}$ of visual experience, while ferrets aged $p \geq 35$ would have had $\sim 3-30 \mathrm{~d}$ of visual experience.

To assess direction selectivity, we recorded the spiking responses of 221 single neurons and 137 multiunit sites to sinusoidal grating stimuli that drifted pseudorandomly in 1 of 8 or 1 of 12 equally spaced directions (spatial frequency: 0.08 cycles per degree, temporal frequency: $4 \mathrm{~Hz}$; 2 s duration, 3.5 s interstimulus interval), along with a blank stimulus of equal duration. Example tuning curves are shown in Figure $1 a$. Because 3-12 h of visual experience with a grating stimulus that moves in a single direction or in a pair of opposite directions is capable of driving the rapid emergence of direction selectivity in naive animals ( $\mathrm{Li}$ et al., 2008; Van Hooser et al., 2012), we used a rapid sampling strategy to limit the amount of visual stimulation that each ani- 
a
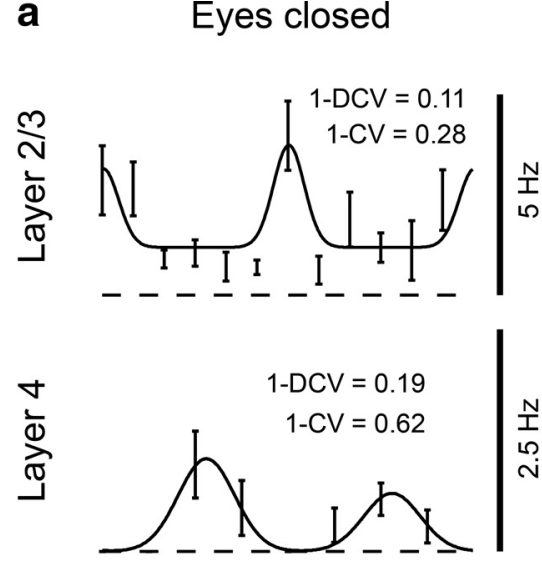

$\uparrow \nearrow \rightarrow \searrow \downarrow と \leftarrow K$
Eyes open, PND $<35$
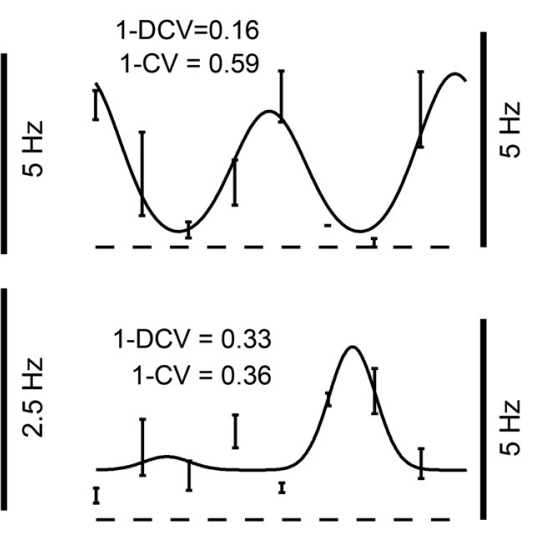

$\uparrow \pi \rightarrow \searrow \downarrow と \leftarrow K$
Eyes open, $\mathrm{PND} \geq 35$
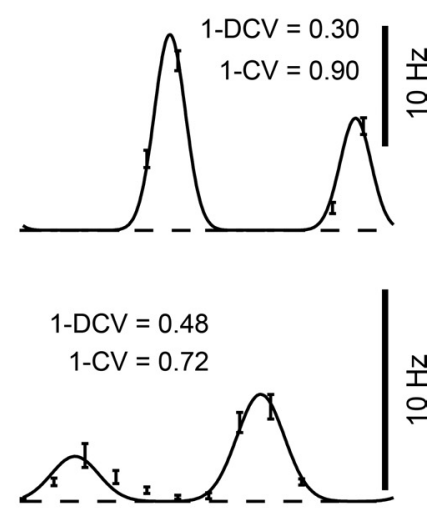

$\uparrow \pi \rightarrow \searrow \downarrow \swarrow \leftarrow \nwarrow$

b

Direction selectivity

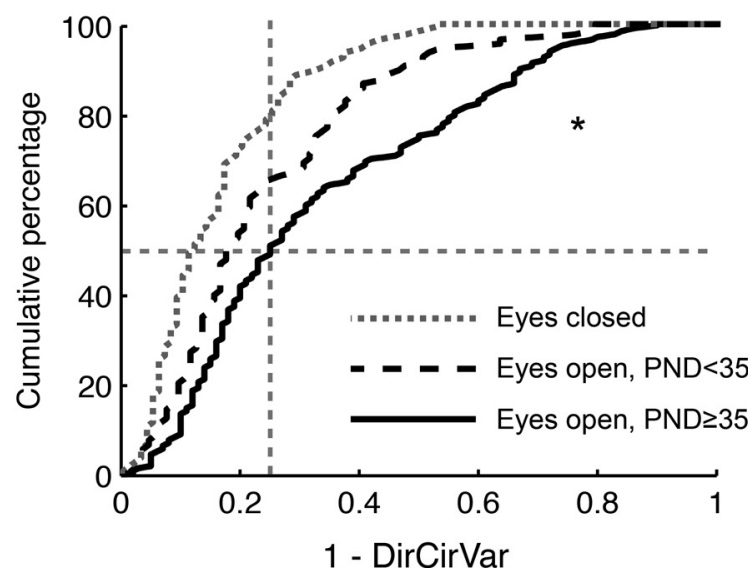

Orientation selectivity

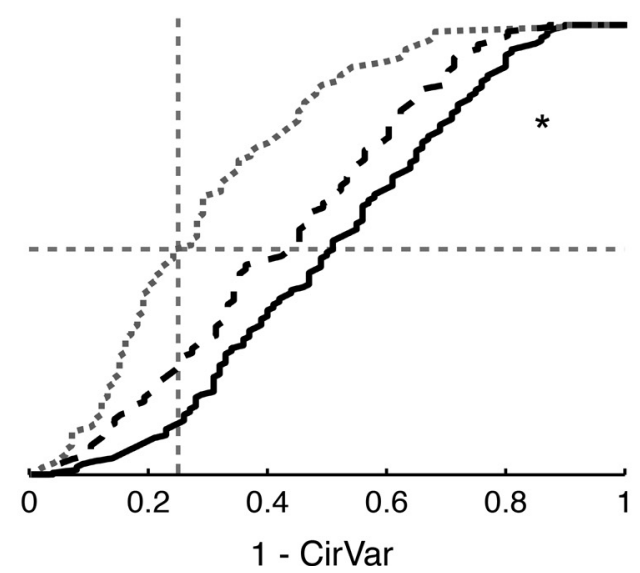

Figure 1. Direction selectivity and orientation selectivity increase in the days following eye opening. $\boldsymbol{a}$, Tuning curves of example cells from layers $2 / 3$ and 4 of $V 1$ from each of the 3 groups. The degree of direction and orientation selectivity is expressed in terms of 1 - circular variance in direction space or orientation space, respectively (see Materials and Methods). $\boldsymbol{b}$, Cumulative percentage of direction and orientation selectivity values across all layers for each age group. * indicates that all differences among groups are significant (Kruskal-Wallis test).

mal received, so that the measurements we made would not be unduly influenced by experience-dependent changes in direction selectivity. First, each neuron was assessed for direction selectivity only, without a separate examination of its preferred spatial frequency, temporal frequency, or receptive field size, in a manner similar to most imaging studies. The spatial and temporal frequencies used here were found in previous imaging studies of developing ferrets (Li et al., 2006, 2008) and pilot electrophysiology studies (this work) to be effective at driving most visually responsive neurons that we encountered; we used full screen stimulation so that the results could be compared directly to prior imaging studies. Second, we presented only 5-7 repetitions of each grating stimulus. Third, each experiment was ended after the animal had been exposed to no more than $3 \mathrm{~h}$ of visual stimulation; this means that the animal observed grating stimulation in each direction for $\sim 3 / 9 \mathrm{~h}$ or $3 / 13 \mathrm{~h}$, and we assumed that this duration of stimulation would not alter receptive fields properties substantially. The validity of these assumptions will be examined in detail after presentation of the main results.

Direction selectivity of spiking responses increases in the days after eye opening

Direction selectivity and orientation selectivity, as assessed at the level of spiking activity, exhibited significant increases across the
3 groups [Kruskal-Wallis test (K-W), $p<0.001, p<0.001$, respectively], as shown in Figure $1 b$. Direction selectivity at the time of eye opening was quite weak, with the median cell exhibiting a 1 - DirCirVar index value of 0.1 , while orientation selectivity was already comparatively strong at eye opening, with a median $1-$ CirVar of 0.25 . These increases in direction selectivity and orientation selectivity with age and experience are very similar to results obtained with intrinsic signal imaging and 2-photon imaging studies (Li et al., 2006, 2008; Van Hooser et al., 2012), suggesting that that are no technical concerns with the interpretation of the blood flow responses or calcium indicator dye responses in these previous studies.

These data also allow us to describe, on average, which features of the spiking tuning curves are altered in the first days after eye opening. We examined a subset of all neurons that exhibited significant orientation tuning (Hotelling's test, $p<0.05$ ) and performed a double Gaussian fit to these tuning curves (Carandini and Ferster, 2000; Li et al., 2008). To make comparisons across cells, we rotated all of these fit curves so that the preferred direction was rightward. The average fits for the 3 groups of animals are shown in Figure 2. To understand how the tuning curves changed, we performed a statistical analysis on the preferred direction response, the null direction (opposite of preferred) response, and the response to the orthogonal orientation. 


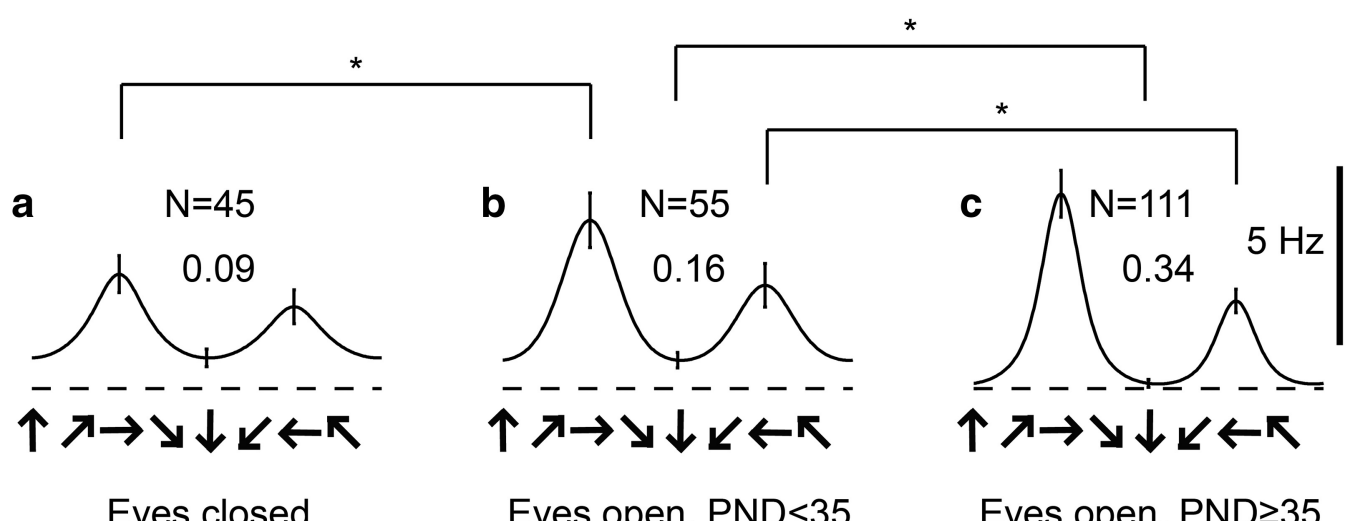

Figure 2. Changes in average spike tuning curves as a function of development. $\boldsymbol{a}-\boldsymbol{c}$, Average tuning curves across all N orientation-selective recording sites for each of the 3 age groups. All curves have been rotated such that the preferred direction corresponds to rightward motion. ${ }^{*}$ indicates differences across conditions that were significant with $p<0.05$ (Kruskal-Wallis test, with Kruskal-Wallis post hoc test). $\boldsymbol{a}, \boldsymbol{b}$, Neurons recorded from animals that had opened their eyes but were less than PND 35 exhibited increased spiking responses to the preferred direction compared with animals whose eyes were closed. $\boldsymbol{b}, \boldsymbol{c}$, Neurons recorded from animals that had opened their eyes and were PND 35 or older exhibited significantly decreased responses to the null direction and orthogonal orientation compared with younger animals.

There was a significant increase in the mean response to the preferred direction between the "eyes closed " and "eyes open, $\mathrm{PND}<35$ ” groups $(\mathrm{K}-\mathrm{W}, \mathrm{K}-\mathrm{W}$ post hoc $\mathrm{p}<0.01$ ), but no evidence for any significant change in the mean response to the null direction or the orthogonal orientation. Further, there was a significant decrease in the response to the null direction $(\mathrm{K}-\mathrm{W}$, $\mathrm{K}-\mathrm{W}$ post $h o c<0.04)$ and the orthogonal orientation $(\mathrm{K}-\mathrm{W}$, $\mathrm{K}-\mathrm{W}$ post hoc $\mathrm{p}<0.001$ ) between the "eyes open, $\mathrm{PND}<35$ " group and "eyes open, $\mathrm{PND} \geq 35$ " group.

\section{Laminar organization of direction selectivity}

A major goal of this study was to determine whether neurons in layer 4 exhibit strong direction selectivity at the time of eye opening or, rather, whether they acquire direction selectivity in the days following eye opening. The laminar organization of direction selectivity is shown in Figure 3. On average, animals whose eyes were still closed at the time of the experiment exhibited very low direction selectivity index values across all layers (Fig. $3 a$, left), and there were no significant differences in 1 - DirCirVar values between layers $2 / 3$ and 4 (Fig. $3 b$, left; K-W $p=0.32$ ). These data suggest that layer 4 does not exhibit substantial direction selectivity at the time of eye opening.

Animals that were examined after eye opening that were less than P35 exhibited increased direction selectivity (Fig. 3a, middle). Layer 4 neurons in these animals showed significantly more direction selectivity compared with layer $2 / 3$ neurons (Fig. $3 b$, middle; $\mathrm{K}-\mathrm{W} p<0.03$ ). In fact, layer $2 / 3$ neurons in animals with open eyes and $\mathrm{PND}<35$ did not exhibit any additional direction selectivity compared with animals whose eyes were closed at the beginning of the experiment (Fig. $3 c$, top, $\mathrm{K}-\mathrm{W}, \mathrm{K}-\mathrm{W}$ post hoc $p=0.38)$. This evidence is consistent with the idea that layer 4 leads layer $2 / 3$ in the development of direction selectivity.

Animals that were PND 35 or older and had open eyes showed considerable direction selectivity in both layers $2 / 3$ and 4 (Fig. $3 a$, right). Layer 4 exhibited higher $1-$ DirCirVar index values than layer $2 / 3$ (Fig. $3 b$, right, $p<0.022$ ). Layer $2 / 3$ neurons in animals PND 35 or older showed increased direction selectivity compared with layer $2 / 3$ neurons in animals with open eyes that were less than PND 35 (Fig. 3c, top; K-W, K-W post hoc $p<0.002$ ). Furthermore, layer 4 neurons in animals older than PND 35 showed a progressive increase in 1 - DirCirVar values over younger an- imals with open eyes and animals whose eyes were closed (Fig. $3 c$, bottom; K-W, K-W post hoc $p<0.007, p<0.004$, respectively).

\section{Laminar organization of orientation selectivity}

In contrast to results obtained for direction selectivity, we observed moderate levels of orientation selectivity in animals whose eyes were closed at the beginning of the experiment (Fig. 4a, left). The moderate orientation selectivity values observed here are consistent with previous studies that documented moderate levels of orientation selectivity in animals lacking visual experience (Li et al., 2006, 2008) and those examined around the time of eye opening (Hubel and Wiesel, 1963; Frégnac and Imbert, 1978; Albus and Wolf, 1984; Braastad and Heggelund, 1985; Blakemore and Price, 1987; Chapman and Stryker, 1993; Ohshiro et al., 2011). Further, these results serve as a control for the weak direction selectivity values we observed in animals whose eyes were initially closed: they indicate that these cells are, in fact, visually responsive, and that they do exhibit some substantial selectivity, albeit not substantial direction selectivity.

The laminar organization of orientation selectivity that we observed here was very similar to that described by Chapman and Stryker (1993). In animals whose eyes were closed at the start of the experiment, we found that cells in layer $2 / 3$ and layer 4 exhibited comparable 1 - CirVar index values (Fig. $4 b$, left, $\mathrm{K}-\mathrm{W} p=$ $0.30)$. Orientation selectivity increased progressively in both layer $2 / 3$ cells and layer 4 cells across the 3 groups of animals (Fig. $4 c$, $\mathrm{K}-\mathrm{W}, \mathrm{K}-\mathrm{W}$ post hoc $\mathrm{p}<0.001$ for both), and in animals greater than PND 35, layer 2/3 cells exhibited slightly higher orientation selectivity values than layer 4 cells (Fig. $4 b$, right; KW $p<0.048$ ).

Like Chapman and Stryker (1993), we encountered fewer cells in the deeper layers. This is not due to a lack of sampling, but rather is related to the very low cell density that is present in layer 5 at this developmental stage (Chapman and Stryker, 1993). However, Chapman and Stryker (1993) did report several cells in layer 6 . To try to sample layer 6 , we conducted 2 experiments specifically targeting layers $4-6$ in the youngest animals, but these experiments also did not yield large counts in layer $5 / 6$ cells. We do not know the reason for the difference between these studies with respect to layer 6 , but it is possible that, because of the very short duration of our experiments, animals were under the influence of both the induction anesthesia (ketamine/xylazine) 
a

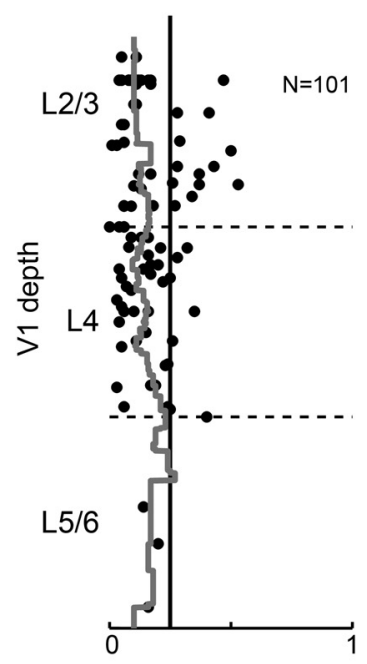

b

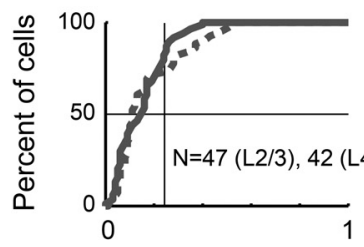

Eyes open, PND<35
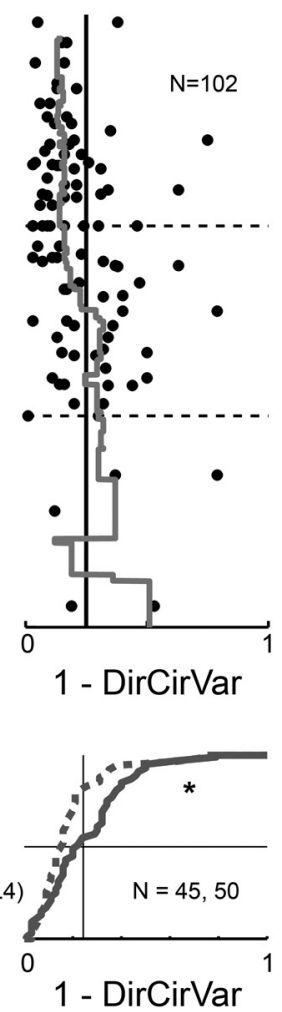

Eyes open, $\mathrm{PND} \geq 35$
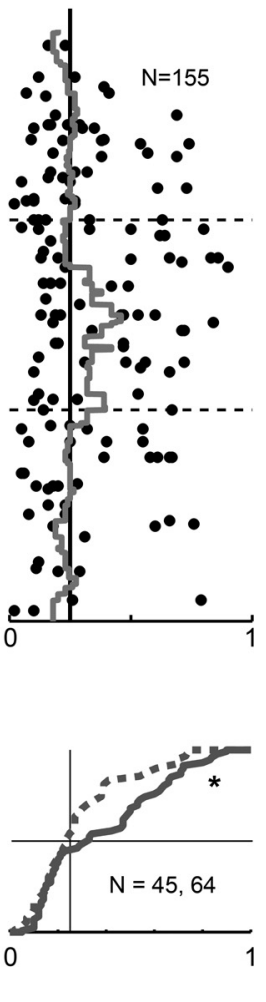
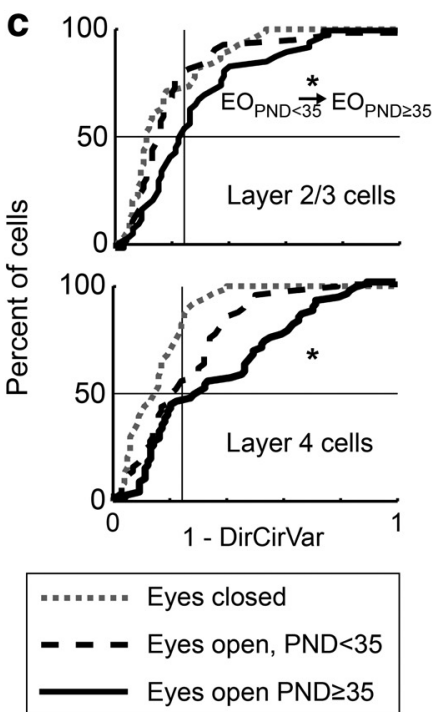

Figure 3. Laminar development of direction selectivity around eye opening. $\boldsymbol{a}$, Direction selectivity of single units recorded from each age group. Each black dot represents a single recording site. The $y$-axis indicates the normalized depth of the recording and the $x$-axis indicates the degree of direction selectivity, expressed as 1 - circular variance in direction space. The gray line running the length of each subfigure is the sliding median of 1 - DirCirVar, descending cortical depth. The vertical black line demarcates substantial direction selectivity, with dots falling to the right of the line exhibiting substantial direction selectivity. The horizontal dashed lines indicate the borders between layers $2 / 3$ and 4 and 4 and $5 / 6$. $\boldsymbol{b}$, Cumulative percentage of direction selectivity in each age group as a function of layer. c, Cumulative percentage of direction selectivity of each layer as a function of age group. Again, the vertical line demarcates substantial direction selectivity. Layer 4 neurons exhibited progressive increases in direction selectivity at each stage, whereas layer $2 / 3$ neurons only exhibited a significant increase in direction selectivity in animals that had opened their eyes and were PND 35 or greater.

and the maintenance anesthesia (isoflurane), which possibly affected activity in layer 6 .

\section{Assumptions of the rapid sampling method}

When we devised the rapid sampling method, we made 2 major assumptions.

First, we assumed that our qualitative conclusions regarding the development of direction selectivity would not have been different if we had optimized spatial and temporal frequency preferences for each cell. This assumption has been made in many multichannel recording studies and 2-photon imaging studies, where optimizing spatial frequency, temporal frequency, and receptive field size for dozens of single cells is impractical (Ohki et al., 2005; Li et al., 2008; Nauhaus et al., 2008). A previous study in the adult cat found that a small minority of direction-selective cells (5/108) dramatically alter their direction selectivity as spatial frequency increases. However, the qualitative property of direction selectivity is preserved across a wide range of spatial frequencies in the vast majority of all cells (Hammond and Pomfrett, 1990). The temporal frequency of the stimulus can have a larger influence on direction selectivity: many cells in adult animals exhibit reduced or reversed direction selectivity when temporal frequency is dramatically increased from a cell's preferred value, and many cells exhibit modestly reduced direction selectivity as temporal frequency decreases from a cell's preferred value (Saul and Humphrey, 1992; Moore et al., 2005). The temporal frequencies used here were set to match the preferred tempo- ral frequency of developing ferrets as observed in previous imaging studies [Li et al., 2006 (see especially their Fig. 4), 2008] and pilot electrophysiology recordings, so a majority of cells were very likely to have been examined using temporal frequencies very near to their preferred values.

Second, we assumed that direction selectivity would not be substantially altered by the limited visual stimulation that was provided during the experiment. This visual stimulation was at most $3 \mathrm{~h}$ total for all directions, and $\sim 1 / 9$ or $1 / 13$ of this time for any particular direction. However, our electrode recordings generally began in the superficial layers and progressed deeper into the brain, so that cells that were recorded at deeper depths were, on average, exposed to more visual stimulation than cells that were recorded at shallower depths (Fig. 5a). This sampling bias raised the possibility that the increased direction selectivity that we observed in layer 4 of animals whose eyes were open at the beginning of the experiment might be due to the extra visual stimulation that these neurons had received by the time of recording, compared with the layer $2 / 3$ neurons. Alternatively, the increased direction selectivity in layer 4 might reflect a difference in receptive field properties that was present at the beginning of the experiment, unrelated to the time course of the experimental measurements. To examine this issue, we plotted the 1 - DirCirVar index value for each cell against the total duration of visual stimulation that the animal had experienced at the time the cell was recorded (Fig. 5b). The relationships between the $1-$ DirCir- 
a

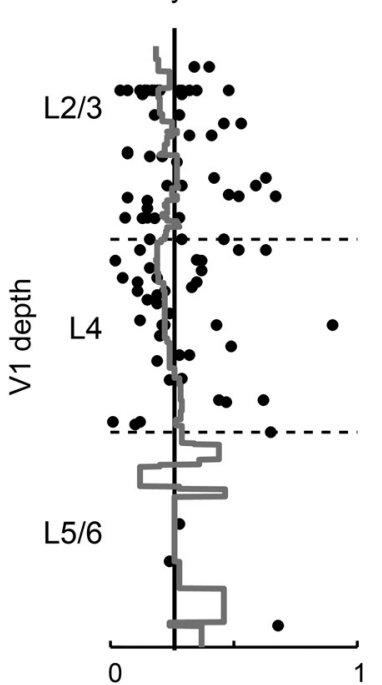

b

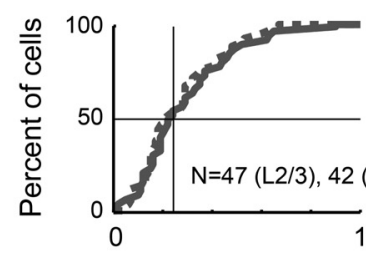

Eyes open, PND $<35$

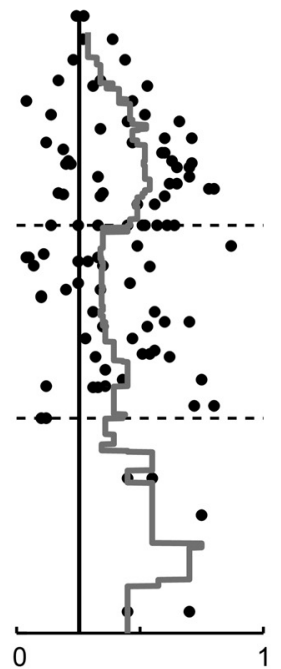

1 - CirVar

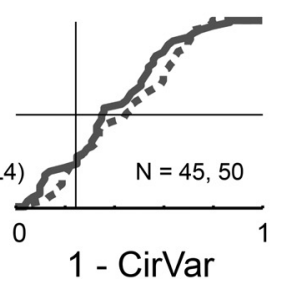

Eyes open, $P N D \geq 35$
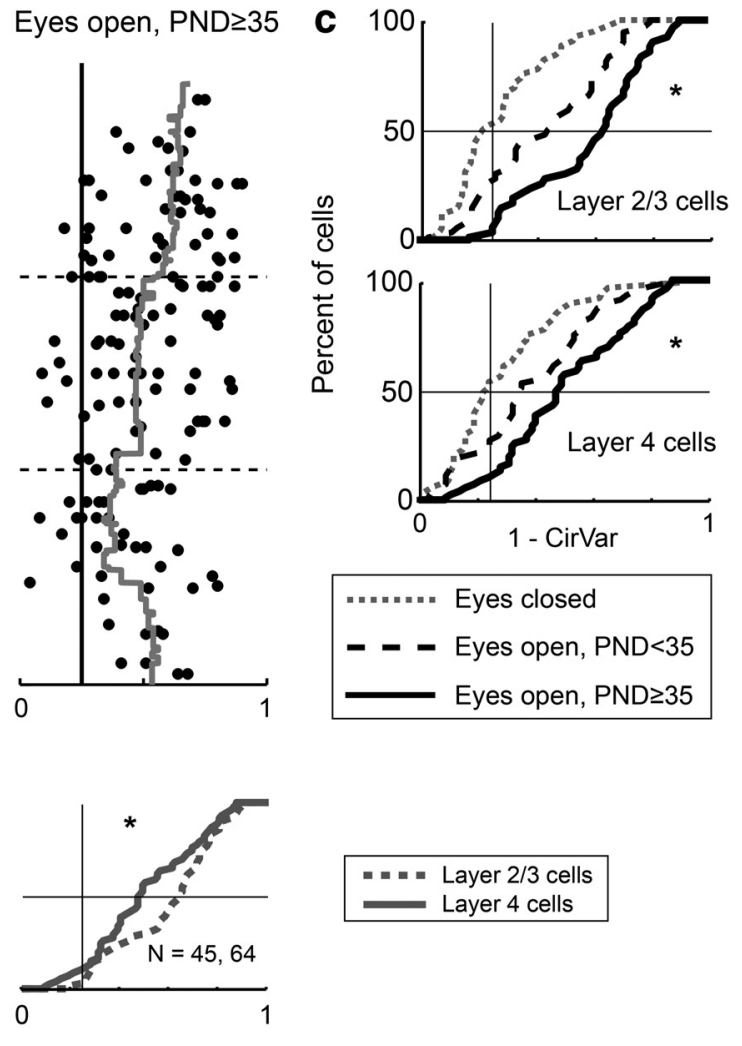

\section{" =" Layer $2 / 3$ cells}

Layer 4 cells

Figure 4. Laminar development of orientation selectivity around eye opening. Identical format to Figure 3 but in reference to orientation selectivity. $\boldsymbol{a}$, Orientation selectivity of single units recorded from each age group. Each black dot represents a single recording site. The $y$-axis indicates the normalized depth of the recording and the $x$-axis indicates the degree of orientation selectivity, expressed as 1 - circular variance. The gray line is the sliding median of 1 - CirVar, descending cortical depth. The vertical black line demarcates substantial orientation selectivity, with dots falling to the right of the line exhibiting substantial orientation selectivity. Horizontal dashed lines indicate the borders between layers $2 / 3$ and 4 and 4 and $5 / 6 . \boldsymbol{b}$, Cumulative percentage of orientation selectivity in each age group as a function of layer. $c$, Cumulative percentage of orientation selectivity of each layer as a function of age group. Vertical line demarcates substantial orientation selectivity. Neurons in layers 4 and 2/3 exhibited progressively increasing orientation selectivity across the examined groups.

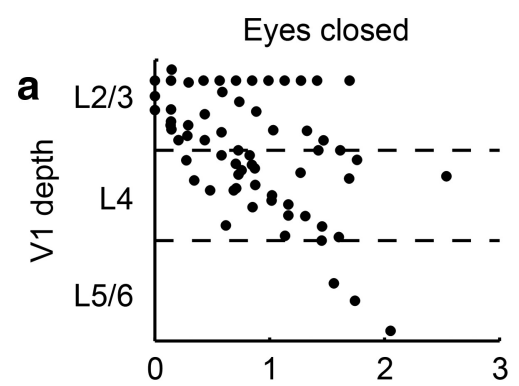

Eyes open, $\mathrm{PND}<35$

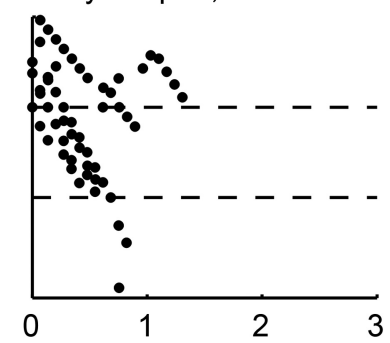

Total stimulation time (hours) Total stimulation time (hours)

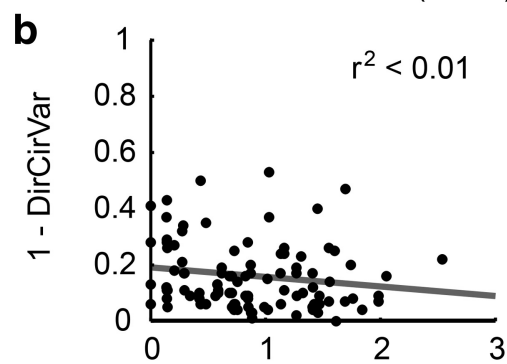

Total stimulation time (hours)

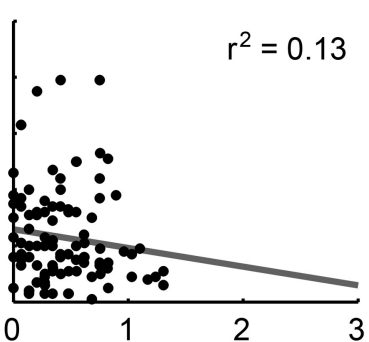

Total stimulation time (hours)

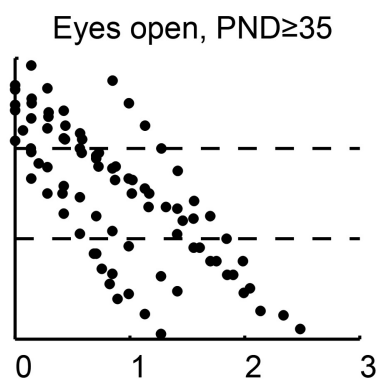

Total stimulation time (hours)

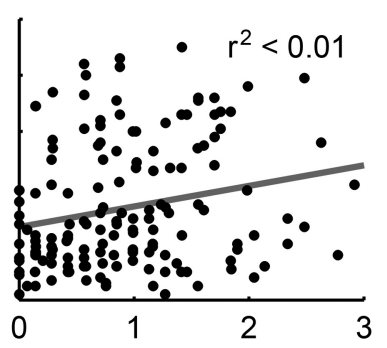

Total stimulation time (hours)

Figure 5. Visual stimulation provided during the experiment did not substantially alter direction selectivity values. $\boldsymbol{a}$, Relationship between the cortical depth of each cell versus the total duration of visual stimulation that had been provided to the animal at the time the cell was recorded. Note that this total duration of stimulation corresponds to the total time of stimulation in 8 or 12 directions plus a blank stimulus, and includes interstimulus intervals ( $63 \%$ of total stimulation time). $\boldsymbol{b}$, Weak relationships between 1 - DirCirVar index values and total stimulation. Lines are linear fits, with the correlation coefficient shown. In an ANOVA, animal group $(p<0.001)$ and cortical layer $(p<0.001)$ explained a significant amount of the variation in $1-$ DirCirVar, but total stimulation time $\operatorname{did}$ not $(p=0.48)$, suggesting that the stimulation provided during the experiment did not alter direction selectivity values. 
Table 1. Summary of the early influence of experience on the development of orientation and direction selectivity in the mouse and ferret

\begin{tabular}{|c|c|c|}
\hline Property & Mouse & Ferret \\
\hline Eye opening & P14 & P27-P32 \\
\hline \multicolumn{3}{|l|}{ Retina } \\
\hline Direction selectivity (DS) & $\begin{array}{l}\text { Develops between P8 and P14 }{ }^{1} \text {; tuning width narrows over next 2-4 } \\
\text { weeks }^{2}\end{array}$ & \\
\hline Altered by dark-rearing? & $\begin{array}{l}\text { Tuning not altered; responses in preferred direction are lower at P14 in } \\
\text { dark-reared animals }{ }^{1,2}\end{array}$ & \\
\hline $\begin{array}{l}\text { Altered by activity } \\
\text { blockade? }\end{array}$ & $\begin{array}{l}\text { Not altered by knock-out of } \beta 2 \text { subunit of the nicotinic acetylcholine } \\
\text { receptor }^{2} \text {; not altered by muscimol or gabazine }{ }^{1}\end{array}$ & \\
\hline Orientation selectivity (OS): & $\begin{array}{l}\text { Present at natural eye opening, increases } 1-2 \text { weeks post-eye open- } \\
\text { ing }^{3} ; \text { fast-spiking interneurons exhibit moderate } 0 \text { S at eye opening } \\
\text { that is reduced after } 1-2 \text { weeks post-eye opening }{ }^{4}\end{array}$ & Present before natural eye opening ${ }^{5,6}$ \\
\hline Altered by dark-rearing? & $\mathrm{No}_{0}{ }^{3}$ (fast spiking interneuron result unknown in dark-reared animals) & No ${ }^{7,8,9}$ \\
\hline $\begin{array}{l}\text { Impact of early } \\
\text { experience }\end{array}$ & $\begin{array}{l}\text { Rearing that restricts viewing to a particular orientation produces an } \\
\text { over-representation of that orientation in cortex }{ }^{10}\end{array}$ & $\begin{array}{l}\text { Lid suture reduces } 0 S^{6,11} \text {; rearing that restricts viewing to a particular orienta- } \\
\text { tion results in over-representation of that orientation; controversial whether } \\
\text { neurons that initially preferred other orientations alter orientation prefer- } \\
\text { ences or merely become unresponsive }{ }^{12,13}\end{array}$ \\
\hline Altered by dark-rearing & $\mathrm{No}^{3}$ & Yes: DS not present in dark-reared animals 7,9 \\
\hline $\begin{array}{l}\text { Impact of early } \\
\text { experience }\end{array}$ & None known ${ }^{3}$ & $\begin{array}{l}\text { Experience with bidirectional motion stimulus causes the emergence of DS such } \\
\text { that some cells prefer } 1 \text { of the stimulated directions and others prefer the } \\
\text { opposite direction }{ }^{8} \text {; Unidirectional training causes majority of cells to de- } \\
\text { velop preference for the trained direction }{ }^{9}\end{array}$ \\
\hline
\end{tabular}

References: ${ }^{1}$ Wei et al. (2011); ${ }^{2}$ Elstrott et al. (2008); ${ }^{3}$ Rochefort et al. (2011); ${ }^{4}$ Kuhlman et al. (2011); ${ }^{5}$ Krug et al. (2001); ${ }^{6}$ Chapman and Stryker (1993); ${ }^{7}$ Li et al. (2006); ${ }^{8}$ Li et al. (2008); ${ }^{9}$ Van Hooser et al. (2012); ${ }^{10}$ Yoshida et al. (2012); ${ }^{11}$ White et al. (2001); ${ }^{12}$ Stryker et al. (1978); ${ }^{13}$ Blakemore and Van Sluyters (1975).

Var index and the total stimulation time were weak, and much weaker than the relationships between total stimulation time and cortical depth (Fig. 5a). To examine this question statistically, we performed a Type-I ANOVA to examine which factors-animal group, cortical layer, and total time of stimulation- explained a significant amount of variance of the 1 - DirCirVar index value, and found that only animal group ("eyes closed," "eyes open, $\mathrm{PND}<35$," "eyes open, $\mathrm{PND} \geq 35$," $p<0.001$ ) and cortical layer $(p<0.001)$ contributed significantly, while total time of stimulation did not $(p=0.48)$. This evidence suggests that the time course of the experiment did not substantially alter our conclusions about the laminar organization of direction selectivity.

\section{Discussion}

We characterized the laminar development of direction selectivity in ferrets around the time of eye opening. We used a rapid sampling protocol to minimize the visual stimulation of the animal, which might have in turn altered the initial selectivity of the neurons. We found that direction selectivity in all cortical layers was weak just before natural eye opening. Layer 4 neurons exhibited increases in direction selectivity that occurred earlier than layer $2 / 3$ neurons, and both of these layers showed robust increases in direction selectivity several days after eye opening. Just after the time of eye opening, increases in direction selectivity were primarily due to increases in spiking responses to the preferred direction, while in subsequent days, increases were primarily due to decreases in spiking responses to the null direction.

\section{Maturation of direction-tuned spike responses}

Direction-selective cells exist in both the retina and the visual cortex (see Table 1). It has been well established that visual experience is not required for direction-selective retinal ganglion cells (DSRGs) to acquire direction selectivity (Daw and Wyatt, 1974; Chan and Chiao, 2008; Elstrott et al., 2008). In cortex, substantial species differences have been noted. In the mouse, direction se- lectivity is present at the time of eye opening, and dark-reared animals also exhibit direction selectivity (Rochefort et al., 2011). However, a class of DSRGs projects directly to LGN in mouse (Huberman et al., 2009; Marshel et al., 2012). A direct connection between DSRGs and LGN has not been demonstrated in other mammals, so the mouse may be unusual in this regard. It is thought that direction selectivity arises anew in the cortex of primates and carnivores. Humans that have experienced vision defects in both eyes during development exhibit profound deficits in motion perception (Ellemberg et al., 2002), suggesting that the human visual system may be like the ferret in that visual experience is required for the normal maturation of direction selectivity.

Some earlier single-unit recording studies in the cortex of visually naive cats, monkeys, and ferrets have noted the presence of direction-selective cells (Hubel and Wiesel, 1963; Wiesel and Hubel, 1974; Hatta et al., 1998; Krug et al., 2001), and indeed we also identified a handful of direction-selective cells in animals whose eyes were closed at the beginning of the experiment. However, it has only recently been demonstrated in imaging experiments that just a few hours of visual experience is sufficient, even in anesthetized animals, to produce direction selectivity ( $\mathrm{Li}$ et al., 2008; Van Hooser et al., 2012). Many of these previous singleunit studies have been traditional serial electrophysiological studies that continued for days, and so many of the reported cells would have had several hours of visual experience with the stimuli that were used in those studies. Here, we used a rapid sampling technique to minimize this concern. We found, consistent with imaging studies, moderate orientation selectivity at the time of eye opening, but generally very weak direction selectivity (Chapman et al., 1996; Li et al., 2006, 2008).

Previous studies of the development of direction selectivity in single cortical cells in ferret used 2-photon imaging of calcium indicator dyes (Li et al., 2008; Van Hooser et al., 2012). Calcium indicator 
dyes can be related to spiking activity in a nonlinear manner (Nauhaus et al., 2012; but see Ohki et al., 2005; Kara and Boyd, 2009), and the concentration of a calcium indicator dye can vary from cell to cell, over time within the same cell, or from experiment to experiment (Stosiek et al., 2003; Li et al., 2008). In our previous studies, we were careful to make statements about direction selectivity and its maturation with visual stimulation-based on the relative responses to the preferred and null directions rather than draw any conclusions about absolute responses. However, a recent study has shown that in vivo calcium indicator dye signals can become saturated, such that larger spiking responses do not cause larger increases in calcium indicator dye signals (Nauhaus et al., 2012), raising the possibility that our previous 2-photon imaging studies may have underestimated direction selectivity.

The spike-based direction tuning curves obtained in these microelectrode experiments were very similar to the fluorescence direction tuning curves that were obtained with 2-photon calcium imaging, suggesting that any saturation of calcium indicator dyes did not adversely impact the conclusions in our previous imaging studies.

These spike-based tuning curves also allow us, for the first time, to describe the changes in absolute spiking responses that explain increases in direction selectivity. On average, increases in spiking responses to the preferred direction explained the initial rise in direction selectivity after eye opening. In subsequent days, a decrease in spiking responses to the opposite direction (and the orthogonal orientation) contributed to further increases in direction selectivity (Fig. 2).

In principle, increases in the response to the preferred direction could reflect an increase in excitatory drive, a decrease in inhibitory drive, or a combination of these factors. Similarly, the reductions in responses to the null direction and orthogonal orientation could reflect decreases in excitatory drive, increases in inhibitory drive, or a combination. However, the fact that opposite changes are observed at different developmental time points suggests that increases in direction selectivity cannot be the result of a single circuit change, such as a nonspecific increase in the overall amount of inhibition in the circuit. Studies of the underlying synaptic conductances will be required to understand the synaptic bases of these changes.

These changes in response tuning are qualitatively different from those observed in ocular dominance plasticity. After 1-3 d of monocular deprivation of the contralateral (dominant) eye, responses to the contralateral eye decrease but responses to the open ipsilateral eye are unchanged; after 5-7 d of continued deprivation, responses to the open eye (and even the closed eye) increase in a process thought to depend on homeostatic plasticity (Olson and Freeman, 1975; Mioche and Singer, 1989; Frenkel and Bear, 2004; Kaneko et al., 2008). A variety of plasticity mechanisms, operating at different time scales and at different developmental times, are likely to be required to mediate appropriate experience-dependent plasticity.

\section{Laminar chronology of the development of direction selectivity}

If we ignore possible contributions from higher visual areas, then there are just 4 major sites within the visual pathway that could be involved in the development of direction selectivity in ferret. The cells we have imaged previously in cortical layer $2 / 3$ receive direct input both from LGN and from cortical layer 4 , and cortical layer 4 receives direct input from the LGN. So, in principle, the development of direction selectivity could involve 1) changes in LGN receptive fields (includes any retinal changes), 2) changes in the pattern of projections from LGN to cortex, 3) changes in the connections from layer 4 to $2 / 3$, or 4 ) changes in recurrent connections within the cortex. The effect of experience on the development of direction selectivity depends on stimulus orientation, so changes in the LGN are unlikely to be sufficient to explain the emergence of direction selectivity. Here, we have focused on understanding how direction selectivity emerges in cortical layer 4 and layer $2 / 3$.

In the first few days after eye opening, layer 4 neurons exhibited significantly higher direction selectivity than layer $2 / 3$ neurons, and layer $2 / 3$ neurons did not exhibit any additional direction selectivity compared with layer $2 / 3$ neurons in animals that had yet to open their eyes. Therefore, layer 4 exhibited increases in direction selectivity at an earlier developmental stage than layer $2 / 3$.

The temporal sequence for the laminar emergence of initial stimulus selectivity such as in the development of direction selectivity may be different from the sequence of events that occurs during reconfigurations of existing receptive field properties, such as in ocular dominance plasticity. Trachtenberg and colleagues found that spike responses and horizontal connections in cat layer 2/3 exhibited dramatic and rapid changes following 1-2 $\mathrm{d}$ of monocular deprivation, while layer 4 exhibited few changes (Trachtenberg et al., 2000; Trachtenberg and Stryker, 2001). These authors speculated that changes in layer $2 / 3$ might direct subsequent plasticity in layer 4 (Thompson, 2000; Trachtenberg et al., 2000). Our data are more consistent with the idea that layer 4 leads the emergence of direction selectivity.

Although layer 4 acquires moderate levels of direction selectivity before layer $2 / 3$, it remains unclear whether layer $2 / 3$ depends on layer 4 for its direction selectivity. In the young mouse, ocular dominance plasticity occurs in parallel in layer $2 / 3$ and layer 4, by distinct mechanisms (Liu et al., 2008), and it is possible that direction selectivity also develops in parallel in layers $2 / 3$ and 4. Both layers receive direct input from the thalamus, as cortical layer 4 receives input from LGN X and Y cells, while layer 2/3 receives input from LGN W cells (Leventhal, 1979; Fitzpatrick et al., 1983). Alternatively, layer $2 / 3$ may inherit direction selectivity from layer 4, but may require a certain level of direction selectivity in layer 4 before direction selectivity is apparent in $2 / 3$. Future multichannel experiments that employ layer-specific blockers will be needed to tease apart these possibilities.

\section{References}

Albus K, Wolf W (1984) Early post-natal development of neuronal function in the kitten's visual cortex: a laminar analysis. J Physiol 348:153-185. Medline

Batschelet E (1981) Circular statistics in biology. New York: Academic.

Blakemore C, Price DJ (1987) The organization and post-natal development of area 18 of the cat's visual cortex. J Physiol 384:263-292. Medline

Blakemore C, Van Sluyters RC (1975) Innate and environmental factors in the development of the kitten's visual cortex. J Physiol 248:663-716. Medline

Braastad BO, Heggelund P (1985) Development of spatial receptive-field organization and orientation selectivity in kitten striate cortex. J Neurophysiol 53:1158-1178. Medline

Brainard DH (1997) The Psychophysics Toolbox. Spat Vis 10:433-436. CrossRef Medline

Carandini M, Ferster D (2000) Membrane potential and firing rate in cat primary visual cortex. J Neurosci 20:470-484. Medline

Chan YC, Chiao CC (2008) Effect of visual experience on the maturation of $\mathrm{ON}-\mathrm{OFF}$ direction selective ganglion cells in the rabbit retina. Vision Res 48:2466-2475. CrossRef Medline

Chapman B, Stryker MP (1993) Development of orientation selectivity in ferret visual cortex and effects of deprivation. J Neurosci 13:5251-5262. Medline

Chapman B, Stryker MP, Bonhoeffer T (1996) Development of orientation 
preference maps in ferret primary visual cortex. J Neurosci 16:6443-6453. Medline

Daw NW, Wyatt HJ (1974) Raising rabbits in a moving visual environment: an attempt to modify directional sensitivity in the retina. J Physiol 240: 309-330. Medline

DiCarlo JJ, Lane JW, Hsiao SS, Johnson KO (1996) Marking microelectrode penetrations with fluorescent dyes. J Neurosci Methods 64:75-81. CrossRef Medline

Ellemberg D, Lewis TL, Maurer D, Brar S, Brent HP (2002) Better perception of global motion after monocular than after binocular deprivation. Vision Res 42:169-179. CrossRef Medline

Elstrott J, Anishchenko A, Greschner M, Sher A, Litke AM, Chichilnisky EJ, Feller MB (2008) Direction selectivity in the retina is established independent of visual experience and cholinergic retinal waves. Neuron 58: 499-506. CrossRef Medline

Fitzpatrick D, Itoh K, Diamond IT (1983) The laminar organization of the lateral geniculate body and the striate cortex in the squirrel monkey (Saimiri sciureus). J Neurosci 3:673-702. Medline

Frégnac Y, Imbert M (1978) Early development of visual cortical cells in normal and dark-reared kittens: relationship between orientation selectivity and ocular dominance. J Physiol 278:27-44. Medline

Frenkel MY, Bear MF (2004) How monocular deprivation shifts ocular dominance in visual cortex of young mice. Neuron 44:917-923. CrossRef Medline

Grabska-Barwińska A, Ng BS, Jancke D (2012) Orientation selective or not?-Measuring significance of tuning to a circular parameter. J Neurosci Methods 203:1-9. CrossRef Medline

Hammond P, Pomfrett CJ (1990) Influence of spatial frequency on tuning and bias for orientation and direction in the cat's striate cortex. Vision Res 30:359-369. CrossRef Medline

Hatta S, Kumagami T, Qian J, Thornton M, Smith EL 3rd, Chino YM (1998) Nasotemporal directional bias of V1 neurons in young infant monkeys. Invest Ophthalmol Vis Sci 39:2259-2267. Medline

Heimel JA, Van Hooser SD, Nelson SB (2005) Laminar organization of response properties in primary visual cortex of the gray squirrel (Sciurus carolinensis). J Neurophysiol 94:3538-3554. CrossRef Medline

Hubel DH, Wiesel TN (1963) Receptive fields of cells in striate cortex of very young, visually inexperienced kittens. J Neurophysiol 26:994-1002. Medline

Huberman AD, Wei W, Elstrott J, Stafford BK, Feller MB, Barres BA (2009) Genetic identification of an On-Off direction-selective retinal ganglion cell subtype reveals a layer-specific subcortical map of posterior motion. Neuron 62:327-334. CrossRef Medline

Kaneko M, Stellwagen D, Malenka RC, Stryker MP (2008) Tumor necrosis factor-alpha mediates one component of competitive, experiencedependent plasticity in developing visual cortex. Neuron 58:673-680. CrossRef Medline

Kara P, Boyd JD (2009) A micro-architecture for binocular disparity and ocular dominance in visual cortex. Nature 458:627-631. CrossRef Medline

Krug K, Akerman CJ, Thompson ID (2001) Responses of neurons in neonatal cortex and thalamus to patterned visual stimulation through the naturally closed lids. J Neurophysiol 85:1436-1443. Medline

Kuhlman SJ, Tring E, Trachtenberg JT (2011) Fast-spiking interneurons have an initial orientation bias that is lost with vision. Nat Neurosci 14: 1121-1123. CrossRef Medline

Leventhal AG (1979) Evidence that the different classes of relay cells of the cat's lateral geniculate nucleus terminate in different layers of the striate cortex. Exp Brain Res 37:349-372. Medline

Li Y, Fitzpatrick D, White LE (2006) The development of direction selectivity in ferret visual cortex requires early visual experience. Nat Neurosci 9:676-681. CrossRef Medline

Li Y, Van Hooser SD, Mazurek M, White LE, Fitzpatrick D (2008) Experience with moving visual stimuli drives the early development of cortical direction selectivity. Nature 456:952-956. CrossRef Medline

Liu CH, Heynen AJ, Shuler MG, Bear MF (2008) Cannabinoid receptor blockade reveals parallel plasticity mechanisms in different layers of mouse visual cortex. Neuron 58:340-345. CrossRef Medline

Marshel JH, Kaye AP, Nauhaus I, Callaway EM (2012) Anterior-posterior direction opponency in the superficial mouse lateral geniculate nucleus. Neuron 76:713-720.

Mioche L, Singer W (1989) Chronic recordings from single sites of kitten striate cortex during experience-dependent modifications of receptivefield properties. J Neurophysiol 62:185-197. Medline

Moore BD 4th, Alitto HJ, Usrey WM (2005) Orientation tuning, but not direction selectivity, is invariant to temporal frequency in primary visual cortex. J Neurophysiol 94:1336-1345. CrossRef Medline

Movshon JA, Thompson ID, Tolhurst DJ (1978a) Spatial summation in the receptive fields of simple cells in the cat's striate cortex. J Physiol 283:5377. Medline

Movshon JA, Thompson ID, Tolhurst DJ (1978b) Receptive field organization of complex cells in the cat's striate cortex. J Physiol 283:79-99. Medline

Nauhaus I, Benucci A, Carandini M, Ringach DL (2008) Neuronal selectivity and local map structure in visual cortex. Neuron 57:673-679. CrossRef Medline

Nauhaus I, Nielsen KJ, Callaway EM (2012) Nonlinearity of two-photon $\mathrm{Ca} 2+$ imaging yields distorted measurements of tuning for V1 neuronal populations. J Neurophysiol 107:923-936. CrossRef Medline

Ohki K, Chung S, Ch'ng YH, Kara P, Reid RC (2005) Functional imaging with cellular resolution reveals precise micro-architecture in visual cortex. Nature 433:597-603. CrossRef Medline

Ohshiro T, Hussain S, Weliky M (2011) Development of cortical orientation selectivity in the absence of visual experience with contour. J Neurophysiol 106:1923-1932. CrossRef Medline

Olson CR, Freeman RD (1975) Progressive changes in kitten striate cortex during monocular vision. J Neurophysiol 38:26-32. Medline

Pelli DG (1997) The VideoToolbox software for visual psychophysics: transforming numbers into movies. Spat Vis 10:437-442. CrossRef Medline

Ringach DL, Shapley RM, Hawken MJ (2002) Orientation selectivity in macaque V1: diversity and laminar dependence. J Neurosci 22:5639-5651. Medline

Rochefort NL, Narushima M, Grienberger C, Marandi N, Hill DN, Konnerth A (2011) Development of direction selectivity in mouse cortical neurons. Neuron 71:425-432. CrossRef Medline

Saul AB, Humphrey AL (1992) Temporal frequency tuning of direction selectivity in cat visual cortex. Vis Neurosci 8:365-372. CrossRef Medline

Stosiek C, Garaschuk O, Holthoff K, Konnerth A (2003) In vivo two-photon calcium imaging of neuronal networks. Proc Natl Acad Sci U S A 100: 7319-7324. CrossRef Medline

Stryker MP, Sherk H, Leventhal AG, Hirsch VB (1978) Physiological consequences for the cat's visual cortex of effectively restricting early visual experience with oriented contours. J Neurophysiol 41:896-909. Medline

Thompson I (2000) Cortical development: binocular plasticity turned outside-in. Curr Biol 10:R348-R350. CrossRef Medline

Trachtenberg JT, Stryker MP (2001) Rapid anatomical plasticity of horizontal connections in the developing visual cortex. J Neurosci 21:3476-3482. Medline

Trachtenberg JT, Trepel C, Stryker MP (2000) Rapid extragranular plasticity in the absence of thalamocortical plasticity in the developing primary visual cortex. Science 287:2029-2032. CrossRef Medline

Van Hooser SD, Heimel JA, Chung S, Nelson SB (2006) Lack of patchy horizontal connectivity in primary visual cortex of a mammal without orientation maps. J Neurosci 26:7680-7692. CrossRef Medline

Van Hooser SD, Li Y, Christensson M, Smith GB, White LE, Fitzpatrick D (2012) Initial neighborhood biases and the quality of motion stimulation jointly influence the rapid emergence of direction preference in visual cortex. J Neurosci 32:7258-7266. CrossRef Medline

Wei W, Hamby AM, Zhou K, Feller MB (2011) Development of asymmetric inhibition underlying direction selectivity in the retina. Nature 469:402406. CrossRef Medline

Weliky M, Bosking WH, Fitzpatrick D (1996) A systematic map of direction preference in primary visual cortex. Nature 379:725-728. CrossRef Medline

White LE, Coppola DM, Fitzpatrick D (2001) The contribution of sensory experience to the maturation of orientation selectivity in ferret visual cortex. Nature 411:1049-1052. CrossRef Medline

Wiesel TN, Hubel DH (1974) Ordered arrangement of orientation columns in monkeys lacking visual experience. J Comp Neurol 158:307-318. CrossRef Medline

Yoshida T, Ozawa K, Tanaka S (2012) Sensitivity profile for orientation selectivity in the visual cortex of goggle-reared mice. PLoS One 7:e40630. CrossRef Medline 